\title{
Improving Bicycle Infrastructure with the use of Bicycle Share Travel Data
}

\author{
Jennifer Weast, Nikiforos Stamatiadis ${ }^{\dagger}$ \\ Keywords: travel demand, bicycle share, bicycle infrastructure \\ https://doi.org/10.32866/001c.12801
}

Transport Findings

\begin{abstract}
This study examines the travel demands and travel patterns in Lexington, Kentucky of SPIN bicycle share users. It is hypothesized that the SPIN users emulate bicycle users on and around the University of Kentucky campus. To identify such demand, travel patterns and routes were compared to existing bicycle infrastructure in order to determine improvement needs. Locations for bicycle infrastructure improvements are recommended.
\end{abstract}

\section{RESEARCH QUESTIONS AND HYPOTHESIS}

This study examines bicycle use and travel patterns of the users of the SPIN bicycle share program in Lexington, Kentucky. The University of Kentucky (UK) serves as a major trip generator and is a popular destination for the bicycle trips including those generated by the SPIN bicycle share program. A similar study conducted by Noland (2019) involved evaluating trip patterns and revenue of e-scooters in Louisville, Kentucky. However, by analyzing bicycle share data, it is hypothesized that SPIN bicycle users emulate general bicycle users on and around campus. Analyzing such travel patterns provides a valuable understanding of bicycle demand and infrastructure needs that may aid UK's mobility goals (University of Kentucky 2015). To identify these needs, travel behaviors and routes were compared to the existing bicycle infrastructure to determine locations for improvement.

\section{METHODOLOGY AND DATA}

Individual bicycle trip data is collected through a GPS locator that is attached to each bicycle. The methods of study include five levels of analysis: length and duration, temporal, climatic, point density, and modeling. The data used in the analysis were obtained from SPIN and consisted of information from individual bicycle trips taken from August 18, 2018 to May 3, 2019. The raw data was cleaned up to exclude trips that showed zero route distance or trip duration as well as trips with unusually high $(>12 \mathrm{mph}[19.3 \mathrm{kph}]$ considered to be a speed for casual bicyclists) or low travel speeds $(<5 \mathrm{mph}[8 \mathrm{kph}]$ considered slower than jogging or walking). A total of 38,505 trips were used in the analysis. For each SPIN bicycle trip, there is a start and end location represented in latitude and longitude coordinates. Route points are also collected throughout the duration of the trip. SPIN is a dockless bicycle share

* Civil Engineering, University of Kentucky

† Univeristy of Kentucky ORCID iD: 0000-0003-3842-2682 
program meaning that a bicycle can be left anywhere that is permitted to leave a bicycle. This type of bicycle share system provides additional insight as to where bicycles have the tendency of being left without the potential consequences if the bicycle was owned, such as theft or vandalism.

\section{FINDINGS}

In the US, the average bicycle trip length ranges from 2.3 to 2.8 miles (3.7 to $4.5 \mathrm{~km}$ ) with an average travel time of about 20 minutes (National Highway Traffic Safety Administration (NHTSA) 2019). The analysis showed that 95.6 percent of the SPIN bicycle trips were 2.5 miles $(4.0 \mathrm{~km})$ or shorter. Furthermore, 94.6 percent of the trips had a travel time of 20 minutes or less. Weekday versus weekend trips were also considered for length and duration analysis. It was found that weekday trips had an average trip length of 0.9 miles $(1.4 \mathrm{~km})$ with an average travel time of 7.9 minutes. Weekend trips were greater in both distance and duration at 1.2 miles $(1.9 \mathrm{~km})$ and 10.9 minutes.

The SPIN bicycle travel data has been further analyzed based on the time of day, day of the week, month of the year, and college semester to determine any temporal trends in ridership usage. Overall bicycle usage trends vary throughout the day. The highest hourly usage occurs at the evening rush hours around 4:00 PM and 5:00 PM. The morning peak period is from 7:00 AM to 10:00 AM with usage increasing at a steady rate during this period. It was also found that Wednesdays had the greatest number of SPIN bicycle trips taken with the weekends having the least amount of usage. Monthly patterns were also observed; it was seen that winter months had a lower number of SPIN bicycle trips than the summer months.

Previous studies have suggested that weather and daily bicycle trips are strongly correlated. Gebhart and Noland (2014) used statistical methods to evaluate the effect of weather on a Washington DC bicycle share system with results showing that cold temperatures, rain, and high humidity reduced the likelihood of using bicycle share and trip duration. Another study in Seattle, Washington identified influencing factors of bicycle travel demand and suggested that people are generally more sensitive to the presence of rain than to the intensity (Schmiedeskamp and Zhao 2016). Another unique finding was a positive linear relationship between daylight hours and count. The analysis of weather trends showed that there was a significantly higher SPIN bicycle usage during the Fall semester than in the Spring semester (Figure 1). The average temperature in the Fall semester (August 22 to December 14) was 57 oF (14 ${ }^{\circ} \mathrm{C}$ ) while in the Spring semester (January 9 to May 3) was $45 \mathrm{oF}\left(7^{\circ} \mathrm{C}\right)$.

To analyze the SPIN data, a generalized linear model (i.e., count model) was developed for predicting the number of SPIN bicycle trips per day. The purpose of this model is to estimate the demand for bicycling on and around campus. Several explanatory variables were considered in the analysis: average temperature $\left({ }^{\circ} \mathrm{F}\right)$, weekday versus weekend $(0=$ weekday, $1=$ weekend $)$, average 
wind speed (mph), precipitation (inches), and average route distance (miles). Table 1 shows the model structure, i.e., variables in the model, their coefficients and significance ( $p$-value) for predicting the number of trips per day. The model has an $\mathrm{R} 2$ value of 0.530 .

A GIS approach is taken to analyze the data and understanding bicycle travel patterns. Point density maps are created to show the intensity of bicycle usage with non-existing bicycle facilities. Figure 2 shows a point density map of route points that are not along an existing bicycle facility such as sidewalks or streets without a bicycle lane. This map was used to identify four routes that should be considered for improvements based on the density of bicycle traffic on nonbicycle facility paths.

The introduction of SPIN bicycles has increased the demand for bicycle parking on UK campus, specifically around classroom buildings and resident halls. As previously mentioned, the dockless bicycle program does not require the bicycle to be docked at designated stations. Figure 3 is a point density map showing areas where SPIN bicycle trips started or ended outside a 50-foot (15.2 $\mathrm{m}$ ) radius of an existing parking location which accounted for 79 percent of the trips. This reveals that users are finding locations that are more convenient than existing bicycle parking facilities. It was recommended that bicycle parking should be expanded or added near major classroom buildings and residence halls based on Figure 3.

This is an open-access article distributed under the terms of the Creative Commons Attribution 4.0 International License (CCBY-NC-4.0). View this license's legal deed at https://creativecommons.org/ licenses/by-nc/4.0 and legal code at https://creativecommons.org/licenses/by-nc/4.0/legalcode for more information. 


\section{REFERENCES}

Gebhart, Kyle, and Robert B. Noland. 2014. "The Impact of Weather Conditions on Bikeshare Trips in Washington, DC.” Transportation 41 (6): 1205-25. https://doi.org/10.1007/ s11116-014-9540-7.

National Highway Traffic Safety Administration (NHTSA). 2019. “Traffic Safety Facts 2017 Data: Bicyclists and Other Cyclists." US Department of Transportation. https://crashstats.nhtsa.dot.gov/ Api/Public/ViewPublication/812765.

Noland, Robert B. 2019. "Trip Patterns and Revenue of Shared E-Scooters in Louisville, Kentucky.” Transport Findings, April. https://doi.org/10.32866/7747.

Schmiedeskamp, Peter, and Weiran Zhao. 2016. "Estimating Daily Bicycle Counts in Seattle, Washington, from Seasonal and Weather Factors." Transportation Research Record: Journal of the Transportation Research Board 2593 (1): 94-102. https://doi.org/10.3141/2593-12.

University of Kentucky. 2015. "Transportation Master Plan: A Strategy for Mobility and Choice.” Lexington, KY: University of Kentucky. 
FIGURES, TABLES, AND SUPPLEMENTARY MATERIALS

1114720_improving_bicycle_infrastructure_with_the_use_of_bicycle_share_travel_data.pdf

Download: https://transportfindings.org/article/12801-improving-bicycle-infrastructure-with-the-use-ofbicycle-share-travel-data/attachment/34483.pdf

\section{0_table1.jpg}

Download: https://transportfindings.org/article/12801-improving-bicycle-infrastructure-with-the-use-ofbicycle-share-travel-data/attachment/34484.jpg

\section{0_figure_3.jpg}

Download: https://transportfindings.org/article/12801-improving-bicycle-infrastructure-with-the-use-ofbicycle-share-travel-data/attachment/34485.jpg

\section{0_figure_2.jpg}

Download: https://transportfindings.org/article/12801-improving-bicycle-infrastructure-with-the-use-ofbicycle-share-travel-data/attachment/34486.jpg

\section{0_figure_1.jpg}

Download: https://transportfindings.org/article/12801-improving-bicycle-infrastructure-with-the-use-ofbicycle-share-travel-data/attachment/34487.jpg 